\title{
Nursing Opportunities Unleashed - A View Point
}

\author{
Prof. U. Bhagyalakshmi \\ Head of the Department, Department of Community Health Nursing, Narayan Nursing College, \\ Gopal Narayan Singh University, Sasaram, Rohtas, Bihar-821305
}

\begin{abstract}
The nursing profession has the widest range of opportunities, but the unawareness and ignorance of nurses are making them be at a dependent level only rather than independent. In most of the scenarios, administrative nurses, health care policymakers, and administrators of institutions and agencies, make and implement roles and activities for nurses to fulfill the aims of medicine and institutional bureaucracy. This problem 'forces' nursing to travel a dependent path.

A view is set forth that the problem stems from the collective failure of nursing to articulate and implement a function and product distinct from that of medicine and other professions. Making this distinction is critical to the charting of an independent path. Nursing's past and present are examined in terms of the service nursing does provide for society.

This paper deals with the various emerging job opportunities for nurses and ways to choose the best working environment for career advancement.
\end{abstract}

Keywords: Teaching Role, Clinical Role, Research Role, Entrepreneur Role, Indian Nursing Council, Migration.

\section{INTRODUCTION}

Reunion with undergraduate, postgraduate batch mates and common peer professional gathering revealed the common challenges which are frustrating nursing faculties, nurses, as well as students also towards the professional aspects. The main concept that draws the attention to write this article is "If anyone stands for something which is right or against any unethical practice, people will focus on the individual correction rather than problem correction" so this article is a combination of reviews, peer discussions, and personal experiences.

\section{Challenges of nursing faculty}

Since last year onwards there are many advertisements for nursing faculty posts in reputed national teaching institutes, for everyone's surprise thousands of people applied for each post. The lowest position offered is having lucrative salaries and monetary benefits. On the contradictory, there are more than one thousand recognized private nursing institutes not paying even half of the proposed salaries in the respective advertisements.

The nursing profession is striving towards excellence with co-existing challenges in day-to-day practices which are unacknowledged or unadmitted through some unseen glass doors at every level and all of them remain unanswered issues. These issues or challenges don't need any pieces of evidence as they are well-known and facts in practice. However still to prove them, either research or a review or a piece of evidence is required in the form of a written complaint which is again a challenging task for nurses to dare with. If at all anyone is coming forward to stand for an issue or challenge, then the person is targeted $360^{\circ}$ instead of targeting the problem or issue. Here are three main perceived challenges or issues faced by the nursing fraternity:

- Job Insecurity leading to exploitationworking setups where there are no set rules and regulations on employment policies, it is evident that nurses are under exploitation. Nurses are often undergoing the pressure of shifting 
roles, position change, or being forced or pressurized to do unacceptable unprofessional things.

\section{- Discrimination- Nurses are} continuously striving for the professional honor and dignity that they deserve. Instead of getting recognition, respect, and reward, this profession face exploitation, the struggle for existence, discrimination, humiliation from their persons, and even from medical colleagues. There is a negative portrayal of this professional image as feminine, menial, subservient roles with low intellect, taken for granted and assistance of physician-only(Saudi journal SK Sharma)

- Migration of Nurses- After seeing the word "Migration" the first thing coming to our mind is that nurses going abroad for higher wages and benefits. Recent studies or shreds of evidence are showing that apart from abroad migration nurses are changing their profession too due to the low wages in the private sector, and the issues of not getting due respect and dignity or no job satisfaction in the profession. Social support from the supervisor and ethical dilemmas is associated with nurses' intention to leave, both directly and indirectly through the mediating role of the meaning of work. For example, unethical practices like various forms of plagiarism leading nurses to shift their careers to other disciplines because of Workplace bullying was found to intensify the intention to leave, increase stress levels, and reduce work performance. The most important consequence was found to be the victim's intention to leave. The identification of individual traits will help organizations pinpoint likely victims of bullying and initiate antivictimization efforts to effectively safeguard individuals in the workplace. Once the nurses are changing their profession they do not prefer to reveal that they are registered, nurses.

\section{Choosing Workplace Smartly-Job Roles Nurses can choose}

Small steps yet game-changing initiatives can be planned and executed at each institute level and individual level, with this intention such kinds of initiatives are listed below:

To address the job insecurities among nurses as well as to address the issues of dignity, respect, and recognition for work their work, one should explore various opportunities by them self's or they can approach any government RTI Online portals or cells, under the provisions of RTI Act, any citizen of India may request information from a "public authority" (a body of Government or "instrumentality of State") which is required to reply expeditiously or within thirty days. This facility can be availed to know the various vacancies or the existence of a nursing cadre in any institute or organization of India. To go with the ideas to explore the opportunities in various working areas like in:

\section{Teaching Roles}

It is a well-known practice that most of the nurses with graduation and above prefer to settle in teaching roles in various settings. As Central \& State Government Teaching institutes are following all the standards in the institutions the challenges faced by the nursing faculty are less compared to private organizations. When nurses are choosing private institutes they should look into a better working environment and job satisfaction along with monetary benefits too. One can choose institutes like:

- University Grants Commission-UGC or National Assessment and Accreditation Council (NAAC) recognized institutes- These institutes will give a broader scope of working environment with multi-disciplinary teams. A wide range of opportunities to collaborate for various academic (curricular, co-curricular, and extracurricular) and research activities, 
in turn, will lead to job satisfaction and career advancement. Set rules, regulations, and institutional policies will address many practical issues positively.

- Group of Institutes- which are recognized by any nationalized regulatory and accredited bodies along with INC

- Newly Starting Institutes- These kinds of institutes will give chance to start everything in a standardized way without the influence of pre-existing hindrances or barriers.

- Online Teaching- Online Tutorials for coaching or any other specific academic requirements based on the availability of the clients.

- Different Teaching Roles- Apart from regular teaching opportunities there are certain specific teaching and training opportunities available in existence like First Aid Course Instructor or CPR Instructor in NGOs like Red Cross, disaster management agencies or organizations, Hospital Instructor or Educator, Nurse Educator.

\section{Clinical Roles}

Apart from regular designations starting from staff nurse to chief nursing superintendent or officer in various central, state government, and private organizations institutions. There are some co-existing nursing roles based on the area of work or the specific job description like:

- Aerospace Nurse- In the aerospace environment, nurses' work is primarily organizational and victim care actions, during all phases of the flight. Aerospace flight nursing is concerned with air evacuation/transport of critically ill and acutely injured patients in military and civilian settings. Specialized training is needed since the sites of evacuation, variable stability of the patients, and the limitations of transport care present challenges. Flight nurses are involved in many phases of medical launch support for the space program, as well. Medical certification, post-landing assessment, and emergency procedures planning and execution represent only a few of the functions for which their expertise is essential. They also contribute to the activities of hyperbaric support for wound care, toxic exposures, and decompression sickness in diving and flying communities. https://www.asma.org/about-

asma/careers/aerospace-nursing. Popular Airlines Companies like IndiGo, Air India, Spice Jet, AirAsia India, and Vistara, etc along with the Job search engines like naukari.com, indeed.com, and timesjob.com, etc are providing opportunities to find jobs as aerospace nurses.

- Travel Nurse-Nurses who are interested in travelling and wants to make it as a career opportunity can choose to become a travel nurse. Most travel companies and agencies are facilitating with a travel nurse also for both domestic \& international tours and travel packages on-demand or some of them gives this service as part of the package also. Websites like travel nurse organizations are providing a detailed description of the process of becoming a travel nurse. Jobs in Skillgigs.com, Apollo Health Care Enterprises Limited, and Stability Health Care Private Limited, etc.

- Sports Nurse or Fitness Nurse- It's an emerging job role in the present scenario. Sports teams and athletic sports programs regularly hire sports medicine nurses. Nurses can support a team part-time or seasonally in addition to another full-time job. Physical rehabilitation facilities and orthopedics offices also hire nurses with experience and credentials in sports medicine

- Cruise Nurse-It's an emerging job role in the present scenario. The ship's nurse is an experienced Registered Nurse (RN) responsible to provide appropriate day-to-day health care to passengers and crew members aboard the cruise ship. 
The cruise ship nurse reports and works under the direction of the ship's lead nurse, ship's physician, and ship's chief doctor. She/ he is called first in case of a medical emergency aboard the cruise ship providing first aid care until the arrival of the ship's physician. The ship nurse performs nursing care in a proficient, calm, and professional manner during routine work shifts as well as during a crisis, increased workload, or emergencies. She/ he initiates nursing intervention for nonurgent patients, such as but not limited to ice application, dressings, splints, and bandages, calculates correct drug dosage, and administers medication as per physician's prescription/order. She/he also assist the physician with procedures/ treatments, document nursing interventions/observations and sets up treatment rooms, checks emergency equipment, maintains established par levels of medical supplies/medications.

https://www.cruiseshipjob.com/nursejobs.html

- Integrated Nurse in AYUSH SettingsThe future for AYUSH Nurses will be booming in a couple of years. National Institute of Ayurveda, Ministry of AYUSH, Government of India, is offering a Diploma Course in AYUSH Nursing and Pharmacy is of $2 \frac{1}{2}$ Years duration including 6 months Internship. Candidates are allotted by the University based on marks obtained in the qualifying examination of 12th Standard. Dr. Sarvepalli Radhakrishnan Rajasthan Ayurved University, Jodhpur is the first Ayurved University of Rajasthan is offering 4 years B.Sc. Ayurved Nursing. The Central Council for Research in Ayurvedic Sciences (CCRAS) is an autonomous body of the Ministry of AYUSH (Ayurveda, Yoga \& Naturopathy, Unani, Siddha, and Homeopathy), Government of India. The Central Council of Indian Medicine is the statutory body constituted under the Indian Medicine Central Council Act, is offering courses for AYUSH Nurses to use complementary and integrative therapies to treat their patients as a whole including mind, body, and spirit. A combination of Eastern and Western medicine, holistic nurses utilize all modalities to teach their patients and communities about wellness and preventative health care.

\section{Research Roles}

- Freelance Researcher- Registered nurses can do individual research as well as they can be a part of any authorized research activities of an organization. Teaching and training people for research expertise either online or offline based on the requirements.

\section{- Research} Nurse/Research Coordinator/Assistant- All the Research-Based State \& Nationalized institutions and organizations are having job positions for research nurses. For example Sri Venkateswara Institute of Medical Sciences- SVIMS, Tirupati, National Institute of Nutrition-NIN, etc.

- Editor and Reviewer- Every journal will be having job roles for editor and reviewer. Official websites of the respective journal will have specific details about it.

- Proof Reader and Content WriterPublishers of nursing books and related journal publications will be offering the job roles for proofreading and content writing.

\section{Entrepreneurship Roles}

A struggle or striving towards getting a job or employability in health care settings is most common among nursing aspirants. As they are unaware of the various opportunities available for them with expanded responsibilities of nurses.

Nursing leadership must raise awareness of implicit bias and help all nurses, from novice to senior, recognize its existence as a barrier to diversity, and create a safe environment to bring concerns, 
identify triggers, and invest in education and training

- Starting or Franchising a Nursing Institute or Hospital- In India almost all the institutes or hospitals are owned by Non-Nursing personal. Nurses can start establishing institutes or hospitals

- Freelancing Flex Jobs-Nurses can work according to their needs and availability. According to the skills they can be a Researcher, Author, Publisher, Research Assistance, Nurse in Clinical Care or Home Care, Teacher, Trainer, Advisor, and Counsellor, etc.

- Start-Ups-Nurses can excel in Startups as they are well known as multitalented, multitask-oriented personalities and skills. Under National policy for women empowerment 2001, the government of India and banks are supporting with financial assistance in the form of subsidy loans at low-interest rates along with some other benefits too. Some of the ideas are as follows:

$\checkmark$ Coaching centers for nursing competitive exams and centers and emerging nursing jobs like travel nurse, research nurse, aerospace nurse, hospice nurse, etc.

$\checkmark$ Agencies to provide nurses for Home Nursing Care, Telenursing, and travel nursing care, etc.

$\checkmark$ YouTube Channel for Teaching and Training.

$\checkmark$ Products and App Creations for nursing care and teaching (Digital books) related aspects in coordination with the companies like Johnson \& Johnson, Novartis, Siemens Healthineers Medtronic India, Messico, Mediplus India Limited, and Jindal Medicot Limited, etc.

\section{Other Opportunities}

Find an interdisciplinary working environment so that you can customize your working style or flex jobs based on your credentials and the needs of the society you are in like:
Multi-National Corporate Sectors- a wide range of opportunities are there in the corporate sector for the nurse as Medical Sales Representatives (Medical Equipment), Medical Advocate, and Clinical Reviewer, etc. companies offering such jobs are Apollo Cradle, Care Health, and Care Foundations, etc.

\section{Medical Coder and Medical} Transcription- All the nurses with graduation are eligible and many multinational companies are established for these specific job roles like Access healthcare, AGS Health Care, Omega Health Care, Johnson \& Johnson, and Cognizant Technology Solutions, etc.

\section{Pharmaceutical}

Companies-

Pharmaceutical companies will be doing continuous research which will be given wider scope to various job roles for nurses in clinical reviewing, teaching, training, supervising, outreach, camping, programs, etc. Companies like Dr.Reddy's Laboratories, Aurobindo Pharma, Sun Pharmaceuticals and Cipla Foundation, etc.

Blogging \& Health Care Writing- Create your blog and publish your ideas or work.

Survey Sites- Nurses are having many roles in healthcare-related survey sites. Government survey organizations like National Family Health Survey of India, District Level of Household \& Facility Survey, Annual Health Survey-Census of India, National Sample Survey OfficeMinistry of Statistics, Survey of India.

Insurance Companies- All the insurance companies and the banks having insurance policies and schemes are preferring nurses as insurance agents or executives at various levels, as they can convince the people medically or logically as well as they can review the medical documents submitted by the beneficiaries. Insurance Companies like Life Insurance Corporation of India-LIC, Aegon Life Insurance Co. Ltd, Aviva Life Insurance Co, Bajaj Allianz Life Insurance Co, Bharti AXA Life Insurance Co, Birla Sun Life Insurance Co, Canara HSBC Oriental Bank of Commerce Life Insurance 
Co, and DHFL Pramerica Life Insurance Co, etc.

Certificate Courses- In both e-Learning mode and in-campus learning( online \& offline mode) various reputed institutions like Indian Institute of Public Health-IIPH and Indian Institute of Nursing NIN ( Many centralized institutes are offering such courses) are giving certificate courses for specific tasks or skills after basic nursing education which is increasing the employability of the nurses like nurse Information technology, biotechnology, bioinformatics, applied nutrition, coding, transcription, artificial intelligence, public health administration, applied research and innovation technology, etc.

Authors- Nurses can write books for all the subject and related disciplines books and publish them. Patents and Copyrights will give good income for nurses.

\section{CONCLUSION}

Nurses should improve their selfesteem and should take a stand for themselves to represent their issues either individually or in a group wherever they are working. Nurses should be able to take bold decisions in terms of adhering to their job description as well as self-respect.

Whatever role a nurse is in teaching, clinical, research, administration, or an entrepreneur if she or he is not maintaining.

\section{Acknowledgement: None Conflict of Interest: None Source of Funding: None}

\section{REFERENCES}

1. Prabhu Navis J. Perspectives: Proud to be a research nurse-be a part of research. Journal of Research in Nursing. 2021 Jun;26(4):354-5.

2. Sando E, Morimoto K, Narukawa S, Nakata K. COVID-19 outbreak on the Costa Atlantica cruise ship: use of a remote health monitoring system. Journal of Travel Medicine. 2021 Mar;28(2):taaa163.

3. Hulsey DM. Influencing Factors on a Nurse's Decision to Remain a Bedside Nurse.
4. Thorne BP. A nurse helps prevent sports injuries. MCN: The American Journal of Maternal/Child Nursing. 1982 Jul 1;7(4):2369.

5. Moc Mo, Learning L. AsMA 91st Annual Scientific Meeting Educational Information. Aerospace Medicine and Human Performance. 2021 Jun;92(6):361.

6. de Morais ÊM, D'Agostini FC, de Oliveira NA. Role of aerospace care nursing in Brazil: Integrative review. Brazilian Journal of Health and Biomedical Sciences. 2021 Jun 2;20(1):63-72.

7. Polk-Walker GC. Aerospace nursing: The new frontier. Journal of Professional Nursing. 1989 Jul 1;5(4):224-30.

8. Çamveren H, Kocaman G. Factors Influencing a University Hospital Nurses' Intentions to Leave the Unit, Organisation and Profession: A Cross-Sectional Study. Journal of Health Management. 2021 Jun;23(2):240-50.

9. Zahednezhad H, Hoseini MA, Ebadi A, Farokhnezhad Afshar P, Ghanei Gheshlagh R. Investigating the relationship between organizational justice, job satisfaction, and intention to leave the nursing profession: A cross-sectional study. Journal of Advanced Nursing. 2021 Apr; 77(4):1741-50.

10. Fletcher K. Image: changing how women nurses think about themselves. Literature review. Journal of advanced nursing. 2007 May;58(3):207-15.

11. Lane IM, Mathews RC, Presholdt PH. Determinants of nurses' intentions to leave their profession. Journal of Organizational Behavior. 1988 Oct 1:367-72.

12. Klein-Collins R. Strategies to Produce New Nurses for a Changing Profession: A Policy Brief on Innovation in Nursing Education. Council for Adult and Experiential Learning (NJ1). 2011.

13. Mitchell R, Finch C, Boufous S, Browne G. Examination of triage nurse text narratives to identify sports injury cases in emergency department presentations. International journal of injury control and safety promotion. 2009 Sep 1;16(3):153-7.

How to cite this article: Prof. U.Bhagyalakshmi. Nursing opportunities unleashed-a view point. International Journal of Research and Review. 2021; 8(11): 17-22. DOI: https://doi.org/10. 52403/ijrr.20211103 